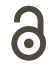

OPEN ACCESS

\section{EDITORES}

- Miguel Oliveira, Jr. (UFAL)

- René Almeida (UFS)

\section{AVALIADORES}

- Alan Motta (UFRJ)

- Ana Quadros (UFRJ)

DATAS

- Recebido: 28/01/2020

- Aceito: 31/03/2020

- Publicado: 28/12/2020

\section{COMO CITAR}

FERREIRA, Luiz Fernando (2020). Modalidade bulética em karitiana. Cadernos de Linguística, v. 1, n. 2, p. 0119

\title{
MODALIDADE BULÉTICA EM KARITIANA
}

\author{
Luiz Fernando FERREIRA (D) D \\ Universidade de São Paulo (USP)
}

RESUMO

Este artigo apresenta um estudo sobre a modalidade bulética em Karitiana (Tupi) à luz dos fundamentos teóricos da semântica formal. Assumiremos que modalidade é a categoria do significado relacionada à expressão de possibilidades e necessidades (VON FINTEL, 2006). Há vários tipos de modalidade. A modalidade bulética está relacionada aos desejos/vontades de um indivíduo. Investigaremos as diferentes formas pelas quais a língua Karitiana gramaticaliza a expressão de desejos e vontades. O corpus analisado contém cento e trinta sentenças coletadas de falantes nativos através de elicitação de dados contextualizada (MATTHEWSON, 2004; SANCHEZ-MENDES, 2014) que foi modificada pelo autor com auxílio de storyboards. Neste artigo, analisaremos três estruturas que são empregadas para veicular modalidade bulética: (i) o morfema desiderativo - wak, (ii) o verbo pyting, e (iii) o verbo py'eep. Esse artigo é relevante na medida em que é o primeiro trabalho especificamente sobre modalidade bulética em Karitiana avançando na descrição de uma língua indígena em risco de extinção. Além disso, algumas características da gramaticalização da modalidade bulética em Karitiana contribuem para o debate teórico em torno da semântica dos verbos que expressam tal modalidade. Comparamos propostas nas quais esses são verbos de atitude proposicional (VON FINTEL; HEIM, 2011; VON FINTEL; IATRIDOU, 2017) com propostas nas quais esses verbos tomam indivíduos como argumentos - e não proposições (KRATZER, 2006; KRATZER, 2016). As propriedades morfossintáticas dos verbos em Karitiana parecem corroborar a proposta que eles não são proposicionais; no entanto, mostraremos que apenas uma análise proposicional fornece uma semântica adequada para esses verbos. 


\section{ABSTRACT}

This paper presents a study about bouletic modality in Karitiana (Tupi) within the theoretical background of formal semantics. We assume modality is the category of meaning associated to the expression of possibilities and necessities and bouletic modality is related to one's wishes and desires (VON FINTEL, 2006). Thus, we explore the different ways through which Karitiana grammaticalizes the expression of wishes and desires. The corpus analysed in this paper has one hundred and thirty sentences collected from native speakers using contextualized data elicitation (MATTHEWSON, 2004; SANCHEZ-MENDES, 2014) which has been modified by the author with storyboards. In this paper, we analyse three different structures that express bouletic modality: (i) the desiderative morpheme - wak, (ii) the verb pyting; and (iii) the verb py'eep. This study is relevant, in first place, because it is the first work to describe bouletic modality in Karitiana, therefore, advancing the description of an endangered language. In second place, some features of the grammaticalization of bouletic modality in this language contribute to the debate on how we are to represent the semantics of those verbs. We have compared the proposals in which those are propositional attitude verbs (VON FINTEL; HEIM, 2011; VON FINTEL; IATRIDOU, 2017) to proposals in which verbs take individuals as arguments and not propositions (KRATZER, 2006; KRATZER, 2016). Superficially, the morphosyntax features of the verbs in Karitiana corroborate the proposal that they are not propositional, however, we show that only a propositional analysis will give an adequate semantics for those verbs.

\section{PALAVRAS-CHAVE}

Modalidade Bulética; Volição; Verbos de Atitude Proposicional; Línguas Indígenas; Semântica Formal.

\section{KEYWORDS}

Bouletic Modality; Volition; Propositional Attitude Verbs; Indigenous Language; Formal Semantics. 


\section{INTRODUÇÃO}

A modalidade está relacionada ao que é possível ou necessário (KRATZER, 1991; VON FINTEL, 2006). Neste artigo, focaremos na modalidade bulética, que é empregada para expressar os desejos de um indivíduo, como ilustrado em (1), que expressa as necessidades de acordo com os desejos do falante.

(1) a. Eu quero tirar férias no Rio de Janeiro.

Uma sentença expressará modalidade bulética quando tratar dos possíveis cenários compatíveis com os desejos de um indivíduo. Na sentença (1), podemos dizer que todos os cenários compatíveis com os desejos do falante são aqueles em que ele tira férias no Rio de Janeiro. Na semântica formal, o termo "mundos possíveis" é tradicionalmente empregado para se referir a esses cenários (KRATZER, 2012).

O objetivo deste artigo é descrever os recursos pelos quais a língua Karitiana (tronco Tupi/família Arikém) expressa modalidade bulética. O Karitiana é uma língua indígena com 400 falantes nativos falada em uma reserva na floresta amazônica no estado de Rondônia.

A metodologia de coleta de dados se embasa na elicitação controlada de dados (MATTHEWSON, 2004; SANCHEZ-MENDES, 2014) que foi complementada nesta pesquisa através: (i) do emprego de Storyboards para apresentar os contextos; e (ii) de testes de verdadeiro ou falso para controlar o nível de atenção dos consultores. Essas mudanças, bem como suas motivações, são descritos na seção 3 . O corpus analisado para este artigo contém, ao todo, cento e trinta sentenças modais. Descreveremos três maneiras de expressar modalidade bulética em Karitiana: (i) o sufixo desiderativo - wak, (ii) o verbo pyting ('querer'); e (iii) o verbo py'eep ('não querer').

A relevância desse estudo se dá por dois motivos. Primeiramente, este é o primeiro estudo que se dedica a descrever a modalidade bulética em Karitiana, ou seja, ele representa um avanço na descrição gramatical de uma língua que está em risco de extinção devido à baixa quantidade de falantes. Em segundo lugar, algumas das maneiras como o Karitiana gramaticaliza essa modalidade são diferentes quando comparadas às línguas mais bem descritas pertencentes ao tronco indo-europeu. Dessa forma, este estudo também ajuda a ampliar nosso conhecimento a respeito das diferentes maneiras pelas quais as línguas do mundo expressam o mesmo significado.

Essas características diferentes dos verbos do Karitiana contribuem para o debate teórico em torno da semântica dos verbos que expressam tal modalidade. Comparamos as propostas nas quais esses verbos tomam uma proposição como argumento sendo verbos de atitude proposicional (VON FINTEL; HEIM, 2011; VON FINTEL; IATRIDOU, 2017) - com propostas nas quais esses verbos tomam indivíduos e não proposições - como argumento 
(KRATZER, 2006; 2016). A priori, os verbos em Karitiana parecem não ser de atitude proposicional, porque seu argumento é sempre um NP (p.ex. sintagmas nominais simples ou sentenças nominalizadas); no entanto, mostraremos que apenas uma análise proposicional fornece uma semântica adequada para os três verbos.

Este artigo se divide em seis seções. A seção 1 apresenta a fundamentação teórica que embasa nossa análise. A seção 2 aborda algumas características da língua Karitiana que são relevantes para o entendimento dos dados. Na seção 3, apresentamos a metodologia na qual a coleta foi baseada, bem como as mudanças que efetuamos nessa metodologia. A seção 4 discute as três formas de expressar modalidade bulética que foram elicitadas por esta pesquisa e qual proposta disponível na literatura consegue fornecer uma semântica adequada. Por fim, a seção 5 traz as conclusões do artigo.

\section{FUNDAMENTAÇÃO TEÓRICA}

Esta seção apresenta alguns pressupostos da semântica formal que embasam a análise feita nesta pesquisa. ${ }^{1}$ Nesse paradigma, modalidade está relacionada com a expressão de necessidades e possibilidades (KRATZER, 1991; VON FINTEL, 2006). Por exemplo, os verbos 'dever' e 'poder' em (2) são considerados modais porque expressam o que é possível/necessário. ${ }^{2}$

(2) João deve/pode estar em casa.

Podemos listar vários tipos de modalidade: epistêmica, deôntica, bulética, entre outras (VON FINTEL, 2006; HACQUARD, 2011). A modalidade epistêmica, como ilustrado em (3a) abaixo, está relacionada ao que é possível ou necessário de acordo com o que sabe a partir das evidências disponíveis. A modalidade deôntica, em (3b), se relaciona ao que é possível ou necessário de acordo com leis, regras ou princípios morais. Por fim, a modalidade bulética, em (3c), está associada ao que é possível ou necessário dados os desejos de um indivíduo.

(3) a. (De acordo com o que sei,) deve/pode estar chovendo.

b. (De acordo com as regras,) visitantes devem/podem ver pacientes neste hospital a partir das 18pm.

c. (De acordo com meus desejos,) devemos/podemos tirar férias no Rio.

1 Apresentaremos o básico sobre modalidade e sobre verbos de atitude proposicional. No entanto, certa familiaridade com os pressupostos da semântica formal e da sintaxe gerativista está pressuposta na análise.

2 A modalidade pode ser expressa através de diversas maneiras (p.ex.adjetivos, advérbios, substantivos), mas, neste trabalho, focaremos na modalidade que é expressa no domínio verbal. 
Como mencionado na introdução, a semântica formal analisa a modalidade como uma quantificação sobre cenários que são chamados, nesse paradigma, de "mundos possíveis" (KRATZER, 2012). O tipo de modalidade é chamado de base modal e está relacionada a como esses mundos possíveis são acessados. Por exemplo, em (3a), são acessados apenas mundos possíveis compatíveis com os conhecimentos (base epistêmica); em (3b), são acessados apenas mundos compatíveis com as regras (base deôntica); e, em (3c), são acessados apenas mundos possíveis compatíveis com os desejos (base bulética).

Observe nas sentenças em (3) acima que verbos modais como 'poder' e 'dever' podem variar na sua base modal de acordo com o contexto. Há outra classe de verbos nos quais a base modal é constante. Por exemplo, o verbo 'achar', ilustrado em (4a), indica que em todos os mundos possíveis compatíveis com as evidências que a Maria tem, está chovendo. Ou seja, a base modal desse verbo é sempre epistêmica. Por outro lado, o verbo 'querer', em (4b), indica que em todos os mundos possíveis compatíveis com os desejos da Maria, está chovendo. Ou seja, a base modal de 'querer' é sempre bulética.

(4) a. Maria acha que está chovendo.

b. Maria quer que esteja chovendo.

Na paradigma tradicional, os verbos em (4) são chamados de verbos de atitude proposicional, uma vez que eles expressam uma atitude de um indivíduo em relação a uma proposição (VON FINTEL; HEIM, 2011; VON FINTEL; IATRIDOU, 2017). Por exemplo, ambos os verbos em (4) expressam uma atitude da Maria em relação à proposição 'estar chovendo'.

Na semântica formal, uma proposição pode ser definida a partir do conjunto de mundos possíveis nos quais ela é verdadeira. Por exemplo, a proposição 'estar chovendo', expressa pelas orações subordinadas em (4), pode ser representada pelo conjunto P de mundos possíveis $w$ nos quais está chovendo como ilustrado abaixo.

(5) $P=\left\{w^{\prime}:\right.$ chove em $\left.w^{\prime}\right\}$

A operação semântica que um verbo de atitude proposicional como 'querer' faz é relacionar o conjunto de mundos possíveis dos desejos (D) ao conjunto de mundos possíveis $(P)$ nos quais a proposição $p$ é verdadeira, de forma que o primeiro seja um subconjunto do segundo, como mostra a figura abaixo: 
(6) a. $\left\{w^{\prime}\right.$ : w’é compatível com os desejos de $x$ em $\left.w\right\} \subseteq\left\{w^{\prime}\right.$ : chove em w'\}

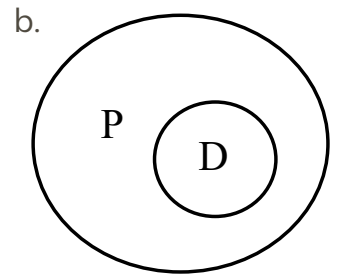

Figura 1. Relação entre conjun-

tos de mundos $\mathrm{P}$ e $\mathrm{D}$

Se o conjunto de mundos possíveis $\mathrm{D}$ está contido no conjunto de mundos $\mathrm{P}$, então todos os mundos D são também P. Em outras palavras, os mundos possíveis dos desejos do Maria são todos mundos possíveis nos quais está chovendo. A análise tradicional para um verbo de atitude proposicional como 'querer' está ilustrada em (7) abaixo (VON FINTEL; IATRIDOU, 2017).

(7) $\llbracket q u e r e r \rrbracket^{w}=\lambda p \cdot \lambda x \cdot \operatorname{des}(x)(w) \subseteq p^{3}$

Lê-se: o verbo 'querer' toma uma proposição $p$ e um indivíduo $x$ e retorna uma sentença que será verdadeira se e somente se o conjunto de mundos possíveis des(x)(w) (i.e. aqueles compatíveis com os desejos de $x$ no mundo da enunciação $w$ ) for um subconjunto do conjunto de mundos possíveis denotados pela proposição $p$.

Mas essa não é a única análise possível para esse tipo de verbo. Kratzer (2006; 2016) propõe uma análise alternativa no qual esses verbos nunca tomam uma proposição como argumento, mas sempre um nome. A semântica que a autora assume está ilustrada em (8) abaixo.

(8) $\llbracket$ querer $\rrbracket^{w}=\lambda x \cdot \lambda$ s. querer $(\mathrm{x})(\mathrm{s})(\mathrm{w})^{4}$

Lê-se: o verbo 'querer' toma como argumentos um $x$ e um estado $s$ e afirma que $s$ é o estado de querer $x$ em $w$.

Dessa forma, na análise de Kratzer (2006; 2016), 'saber' e 'querer' não são verbos de atitude proposicional. Como o verbo não toma essa subordinada como argumento, a autora propõe uma outra maneira pela qual o verbo se compõe com uma proposição como 'estar chovendo' em (4). Para ela, o complementizador 'que' toma essa proposição e a transforma

3 A notação $\subseteq p$ pressupõe que $p$ é um conjunto de mundos possíveis, o que não é verdade. $p$ é uma função que toma mundos possíveis e retorna valores de verdade. No entanto, nos permitiremos representar o conjunto de mundos possíveis no qual a proposição é verdadeira pela função $p$.

4 Note que o $x \mathrm{em}(7)$ se referia ao sujeito que era argumento externo do verbo e $p$ se referia ao argumento interno. Em (8), $x$ se refere ao argumento interno, ou seja, ao objeto. Nessa proposta, o sujeito não é um dos argumentos do verbo. Para uma sentença como (4b), esse modelo assume uma estrutura sintática na qual o sujeito é introduzido posteriormente por vP como ilustrado abaixo. O papel de vintroduz Maria como a possuidora do estado de querer que esteja chovendo. Dessa forma, $\llbracket v \rrbracket=\lambda x \lambda s \lambda w$. POSSUIDOR(x)(s)(w).

i. [ Maria [vPv [VP quer [CP que [VP esteja chovendo] ] ] ] 
em um predicado, como em (9) abaixo. A partir da semântica dada para o complementizador, a subordinada 'que esteja chovendo' teria a semântica ilustrada em (10).

(9) $\llbracket q u e \rrbracket=\lambda p \lambda x \cdot \forall w^{\prime}\left[\operatorname{compatible}(x)\left(w^{\prime}\right) \rightarrow p\left(w^{\prime}\right)\right]$

Lê-se: o complementizador 'que' toma uma proposição $p$ e retorna um predicado no qual para todo mundo $w^{\prime}$ com o qual $x$ é algo compatível, então $w^{\prime}$ é um mundo no qual a proposição é verdadeira.

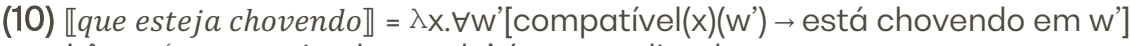

Lê-se: 'que esteja chovendo' é um predicado que toma como argumento um $x$ e afirma que para todo mundo $w^{\prime}$, se $x$ é compatível com w', então está chovendo em $w$ '.

A composição semântica do verbo 'querer' com a subordinada se dá através da operação Restrict, que junta dois predicados (CHUNG; LADUSAW, 2003). A composição de 'querer' com 'que esteja chovendo' através da operação Restrict teria o seguinte resultado:5

(11) $\llbracket q u e r e r$ que esteja chovendo $\rrbracket^{w}=\lambda x . \lambda s . q u e r e r(x)(s)(w) \& \forall w^{\prime}\left[\right.$ compatível $(x)\left(w^{\prime}\right) \rightarrow$ está chovendo em w']

Lê-se: 'querer que esteja chovendo' é um predicado que toma como argumentos um $x$ e um $s$, e afirma que $s$ é o estado de querer $x$ em $w$ e para todo mundo $w$, se $x$ é compatível com w', então está chovendo em $w$ '.

Esta seção apresentou o aporte teórico sob o qual será realizada a análise na seção 5 dos itens elicitados. A próxima seção apresenta algumas características da gramática do Karitiana que são relevantes para o entendimento dessa análise.

\section{A LIINGUA KARITIANA}

As estruturas na língua Karitiana que expressam modalidade bulética descritas nesta pesquisa são de dois tipos: (i) morfologia verbal e (ii) verbos. O objetivo desta seção é apresentar algumas propriedades da morfologia verbal e de verbos em Karitiana que serão relevantes para o entendimento dos dados apresentados na seção 5.

Os verbos da língua Karitiana se organizam da seguinte forma: prefixo de pessoa, prefixo de tipo sentencial, prefixo de modalidade, raiz verbal e sufixo de tempo, como ilustrado em (12) (FERREIRA, 2017a; 2017b). 
(12) Pongyp $\emptyset$-na-pyn-taraka-t ${ }^{6}$

quieto 3-decl-deo-andar-nfut

'Deve-se ficar quieto'(Narrativa Osiipo)

No entanto, há dois contextos nos quais os morfemas de tipo sentencial e tempo não estão presentes: (i) orações negativas, como em (13a), e (ii) orações subordinadas, em (13b) (STORTO, 2002; 2012). ${ }^{7}$

(13) a. Y-otam padni yn

1.SG-chegarNEG 1.SG

'Eu não cheguei'(STORTO, 2018, p. 228)

b. [Y-opiso] a-taka-kãra-t an

[1SG-ouvir] 2.SG-DECL-pensar-NFUT 2.SG

'Você achou que eu ouvi'(STORTO, 2002, p. 154)

Para dar conta da ausência de morfologia de tipo sentencial e de tempo nesses ambientes, Storto (2012) argumenta que as subordinadas só possuem sintagma aspectual, não havendo os sintagmas de tempo e tipo sentencial que estariam acima do aspecto. No entanto, Vivanco (2018) apresenta uma proposta alternativa, na qual as orações subordinadas no Karitiana são todas nominalizadas. A ausência de tempo seria apenas um dos indícios dessa nominalização. Primeiramente, Vivanco (2018) mostra que a nominalização de orações subordinadas é um fenômeno comum nas línguas Tupi. Então, a autora observa que orações subordinadas em Karitiana recebem marcação de caso, como mostra a sentença em (14), na qual a subordinada é marcada para caso oblíquo. Como a marcação de caso é uma propriedade nominal, a autora assume que essa é uma outra evidência de que a subordinada em (14) é um NP. Por fim, o último argumento de Vivanco (2018) é a ausência de complementizadores como 'que', que introduzem orações subordinadas.

(14) [lpi-ty

Maria ti'y-ka ]-ty

$\varnothing$-na-pyting- $\varnothing$

José

[peixe-OBL

Maria comida-fazer]-OBL

3-DECL-querer-NFUT José

'José quer que Maria cozinhe peixe.'

6 As glosas que empregamos são: 1 = primeira pessoa; 2 = segunda pessoa; 3 = terceira pessoa; $A D V$ = adverbializador; $\mathrm{COP}$ = cópula; $\mathrm{DECL}$ = declarativo; $\mathrm{DEO}$ = deôntico; $\mathrm{DES}$ = desiderativo; FUT = futuro; $\mathrm{N}$ = não-; NEG = negação; OBL = oblíquo; $\mathrm{SG}=$ singular.

7 Questões são outro tipo de sentença que não possuem morfologia nessa língua. As questões na língua não serão apresentadas aqui uma vez que não serão relevantes para este artigo. 
Consideramos os argumentos de Vivanco (2018) mais plausíveis e seguiremos a proposta da autora de que as orações subordinadas são nominalizadas. Dessa forma, uma tradução mais adequada para a sentença (14) acima seria algo como 'José quer o cozimento do peixe da/pela Maria'. A nominalização de subordinadas e a morfologia verbal são as propriedades que serão relevantes para a análise desenvolvida na seção 4 . A próxima seção apresenta a metodologia empregada na coleta de dados.

\section{METODOLOGIA}

Seguimos a metodologia de elicitação controlada de dados proposta em Matthewson (2004) e Sanchez-Mendes (2014). Essas propostas argumentam que a mera tradução não é suficiente para uma análise semântica, uma vez que a sentença pode ter uma ambiguidade ou vagueza da qual o/a pesquisador(a) não se deu conta na elaboração do questionário, o que pode fazer com que o consultor forneça uma sentença na língua nativa cujo significado difere daquele que o/a pesquisador(a) pretendia coletar. Por exemplo, imagine que o/a pesquisador(a) deseja saber como uma determinada língua expressa diferentes modalidades buléticas. Ele/ela, então, elabora sentenças com quantificação universal (necessidades) e existencial (possibilidades), conforme ilustrado abaixo:

1. Como você falaria "A gente pode tirar férias no Rio." na sua língua? 2. Como você falaria "A gente tem que tirar férias no Rio." na sua língua?

Figura 2. Exemplo de Elicitação com Tradução Simples

Como vimos na seção 1, os verbos como 'poder' e 'ter que' são vagos em relação ao tipo de modalidade que expressam. Dessa forma, o fato de o/a pesquisador(a) ter em mente a modalidade bulética no momento de elaboração do questionário da figura 2 não garante que o consultor terá a mesma modalidade em mente na realização da tradução. O consultor pode considerar um contexto no qual se ganhou uma viagem e que se pode/tem que tirar férias no Rio para aproveitar a viagem gratuita (modalidade circunstancial), ou um contexto no qual duas pessoas estão em um trabalho que exige que eles viajem de estado em estado e que, pelas regras da empresa, eles podem ou devem tirar férias quando chegarem no Rio (modalidade deôntica). O fato é: o consultor pode dar várias interpretações para a sentença em português que o/a pesquisador(a) não pensou no momento de elaborar o questionário e que fogem do escopo da pesquisa. Esse tipo de elicitação se chama elicitação controlada de dados porque a presença de contextos auxilia no controle do tipo de interpretação desejada, como ilustrado abaixo. 
Um casal está conversando sobre suas férias. O marido pensou em dois lugares para os quais ele deseja ir: Rio de
Janeiro e Fernando de Noronha. A esposa pergunta para onde ele quer ir e ele responde "A gente pode tirar férias
em Fernando de Noronha", mencionando umas das possibilidades que ele tinha em mente. Como essa sentença
seria dita sua língua?
O marido pergunta para a esposa o que ela acha da sugestão dele. Ela não fica feliz, porque só tem um lugar para
o qual deseja ir: Rio de Janeiro. Então, ela responde ao marido "A gente tem que tirar férias no Rio" para dizer que
aquele é o único lugar para o qual ela quer ir. Como essa sentença seria dita na sua língua?

Figura 3. Exemplo de Elicitação Controlada de dados

No entanto, essa metodologia possui algumas lacunas. Como afirma Louie (2015), dependendo da quantidade de sentenças, a presença dos contextos pode deixar o questionário extremamente longo e cansativo para o consultor. Por exemplo, imagine que o pesquisador queira coletar cem sentenças na língua. Ele deverá elaborar um contexto para cada sentença de modo que o consultor deverá escutar cem contextos que são muito parecidos.

O consultor, sabendo que a única tarefa que ele terá de executar após a apresentação do contexto será a tradução, ele tende, depois de certo tempo, a ignorar os contextos e só prestar atenção quando se fala a sentença que ele sabe que precisará traduzir. Ou seja, a presença do contexto passa a ser indiferente, uma vez que, na prática, o consultor está fazendo uma simples tradução descontextualizada, o que é condenado em Matthewson (2004) e Sanchez-Mendes (2014).

Outra questão que podemos enfrentar é o não entendimento do contexto pelo consultor. Os consultores Karitiana são falantes nativos de Karitiana, mas aprenderam Português como segunda língua. A fluência dos consultores em Português é muito variada, de modo que é difícil de saber, ao trabalhar com um consultor, se ele está entendendo os detalhes do contexto que são relevantes para o tipo de fenômeno estudado.

Para sanar esses problemas, a elicitação de dados realizada nesta pesquisa foi modificada de três maneiras. A primeira foi não apresentar contextos curtos antes de cada sentença, mas contar uma história. Essa história contextualizaria não uma sentença, mas um grupo de aproximadamente dez sentenças. Isso diminui a quantidade de contextos aos quais o falante precisa prestar atenção e torna a coleta de dados menos cansativa.

Outra modificação foi empregar ilustrações para apresentar essas histórias, de modo que as sentenças foram contextualizadas com uso de storyboards. Dessa forma, as histórias eram narradas pelo pesquisador ao mesmo tempo em que eram mostradas imagens para ilustrá-las. Um dos storyboards usados pela pesquisa está ilustrado na figura 4 abaixo. ${ }^{8}$

8 Todas as imagens utilizadas na elaboração dos storyboards foram obtidas em sites na internet. As imagens que ilustram o storyboardnesse artigo foram obtidas em um site de distribuição gratuita de imagens PNG https://pngtree.com/ [acessado em 28 de Janeiro de 2020]. A imagem das pessoas é de 'As adult PNG' feita pelo usuário icontree e as imagens dos carros é de 'high speed rail PNG' feita pelo usuário 588ku. A elaboração das histórias e as montagens das imagens foram realizadas pelo autor. 


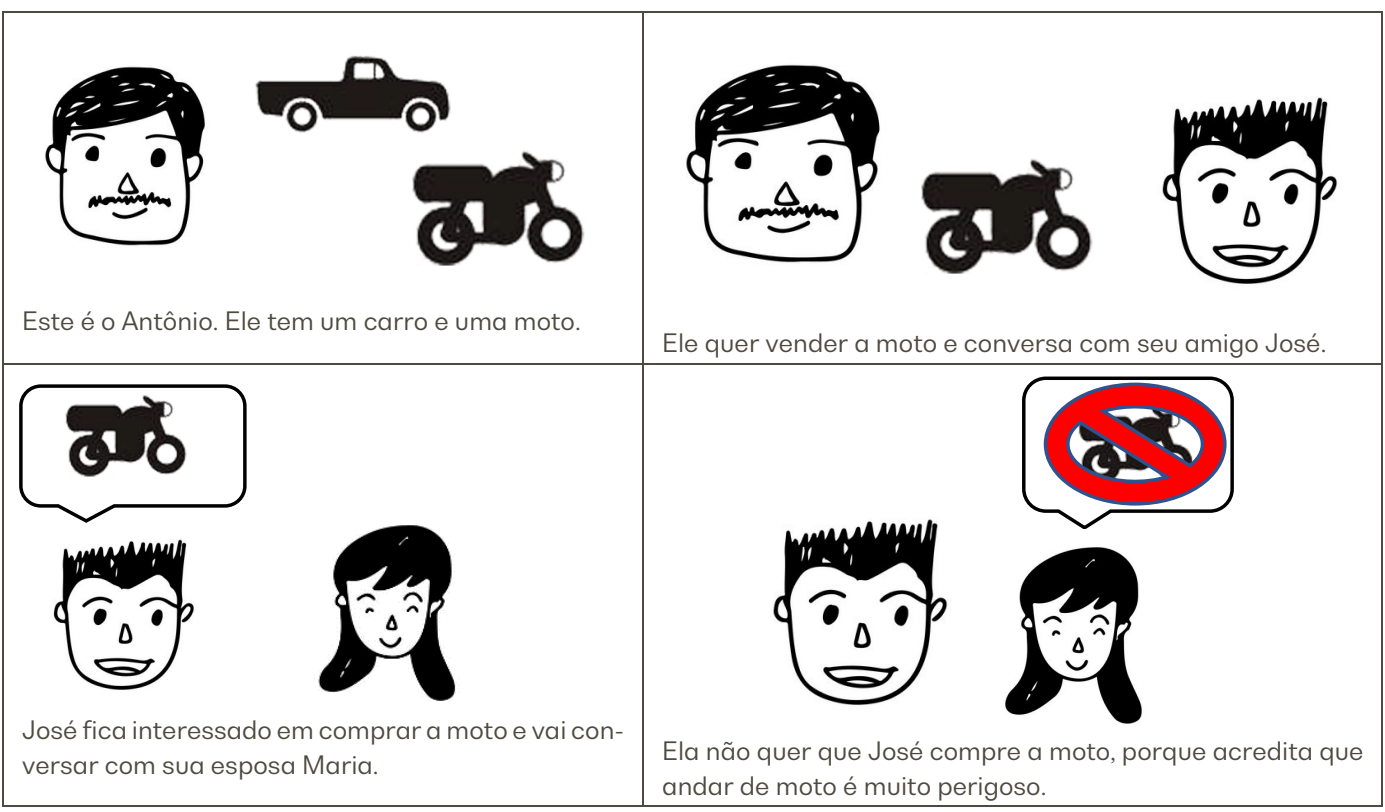

Figura 4. Exemplo de Storyboard

O objetivo do uso de storyboards foi deixar a apresentação dos contextos menos enfadonha e tentar manter o interesse do informante por mais tempo, além de facilitar o entendimento do contexto para aqueles consultores com menor fluência no português. O uso de storyboards pareceu manter a atenção dos informantes por mais tempo, mas não garantiu que, após certo tempo, o consultor pare de prestar atenção. Dessa forma, fizemos uma terceira mudança na metodologia com a criação de um teste de verdadeiro ou falso após a apresentação de cada história, como se vê na figura 5. Com isso, promovemos uma maior concentração do consultor na história, pois, sabendo que haveria questões após a história para testar seu entendimento, o consultor prestava mais atenção no contexto. Além disso, esse teste nos forneceu um feedback do quanto o falante compreendeu daquilo que foi contado e dos níveis de atenção durante toda a elicitação.

\begin{tabular}{|c|c|}
\hline \multicolumn{2}{|c|}{ De acordo com a história que você acabou de ouvir, coloque (V) se a sentença for verdadeira ou (F) se for falsa. } \\
\hline Antônio quer vender o carro. & ) \\
\hline Antônio quer vender a moto. & ) \\
\hline José quer o moto. & ) \\
\hline José quer a carro. & ) \\
\hline Maria não quer que José compre o carro.( ) & ) \\
\hline Maria não quer que José compre a moto. ( ) & ) \\
\hline
\end{tabular}

Figura 5. Exemplo de teste após o contexto

Dessa forma, a confiança nos dados cresce à medida que o consultor acerta as perguntas de verdadeiro ou falso. Como o objetivo final de um trabalho em semântica formal é descrever como um item lexical, partícula ou morfema influencia nas condições de 
verdade de uma sentença, é fundamental para um semanticista saber se o falante tem ciência das condições de verdade do contexto ao qual ele foi apresentado e que podem tornar a sentença que ele está traduzindo verdadeiras ou não. Foi somente após esse teste que se solicitou ao consultor que realizasse a tradução das sentenças.

Esse ainda não é último passo. Após a elicitação contextualizada, Sanchez-Mendes (2014) defende que deve haver um momento de análise de dados e criação de hipóteses sobre as diferenças semânticas entre os itens que foram elicitados na tradução contextualizada e testar se as condições de verdade das sentenças confirmam ou não essas hipóteses. Para isso, as sentenças em Karitiana devem ser apresentadas em vários contextos, observando se os falantes aceitam que a sentença seja usada ou não naquele contexto. Por exemplo, na elicitação coletamos o verbo py'eep que os falantes traduziram como 'não querer'. No entanto, no momento de descrever a semântica desse verbo, ficou a dúvida se a negação estaria no escopo da modalidade (p.ex.'Maria não quer que João compre a moto')

ou se a modalidade estava no escopo da negação (p.ex.'Não é verdade que Maria quer que João compre a moto'). No primeiro caso, todos os mundos do desejo da Maria são mundos nos quais João não compra a moto. No segundo caso, Maria é indiferente à compra da moto e há mundos possíveis compatíveis com os desejos dela nos quais João compra a moto e mundos possíveis nos quais ele não compra. Para compreender melhor a semântica de py'eep, sentenças contendo esse verbo foram apresentadas aos informantes em diversos contextos, como ilustrado abaixo.

(15) Pesquisador: Suponha que José está planejando comprar uma moto. Aí alguém na aldeia te fala o seguinte 'Maria naakat ipy'eep Antônio mototy José amyty.' Se o José comprar a moto, você acha que a Maria vai ficar brava?

Consultor: Muito brava, é capaz até de capar ele.

O objetivo desta seção foi exatamente mostrar metodologias para contornar os eventuais desvios de interpretação por parte do consultor. Partimos na elicitação controlada de dados, mas enriquecendo a apresentação dos contextos com storyboards e acrescentando métodos de controle de atenção. Defendemos que essas alterações tiveram impactos positivos uma vez que os informantes se mostraram mais atentos nessa coleta do que em coletas apenas com apresentação do contexto. A próxima seção apresentará a análise dos dados elicitados. 


\section{ANÁLISE}

O objetivo desta seção é apresentar uma análise para os itens lexicais que foram empregados para expressar modalidade bulética no Karitiana. Os consultores expressaram modalidade bulética através do sufixo desiderativo - wak e a partir dos verbos: pyting e py'eep. Em um primeiro momento, o fato de que pyting e py'eep tomam sentenças nominalizadas parece ser um indício de que esses verbos não são proposicionais e que uma análise que siga Kratzer (2006; 2016) seja a mais adequada para eles. No entanto, argumentaremos que apenas uma análise proposicional consegue fornecer uma semântica satisfatória para ambos os verbos.

\subsection{O SUFIXO -WAK}

O Karitiana pode marcar desejos através de um sufixo verbal, como em (16): ${ }^{9}$

$\begin{array}{rll}\text { (16) Maria } & \varnothing \text {-na-byhipi-wak } & \text { 'ip } \\ \text { Maria } & \text { 3-DECL-cozinhar-DES } & \text { peixe }\end{array}$

'Maria quer cozinhar peixe.'

Nesta subseção, apresentamos uma semântica para - wak e propomos como se dá a composição semântica com os demais itens da sentença. Para isso, vamos investigar algumas possibilidades de composição antes de apresentar aquela que deriva o significado da sentença corretamente. Primeiramente, poderíamos assumir que - wak tem a proposição toda no seu escopo, como se vê abaixo em (17). Uma segunda opção é assumir que 'Maria' se move e deixa um vestígio em sua posição de origem, de acordo com (18):10

(17) [wak [vPMaria[vpbyhipi ‘ip ]]

(18) [Mariai [wak [vpti byhipi 'ip ]]]

9 A posição de -wak não parece corroborar a proposta apresentada na seção 2 de que os morfemas que marcam modalidade são prefixos. O Karitiana possui uma série de verbos auxiliares que ocorrem após o verbo principal que possuem uma semântica modal/aspectual. Uma hipótese é que - wakera um verbo auxiliar que foi reinterpretado como um morfema preso e, por esse motivo, ele aparece como sufixo, enquanto outros morfemas que expressam modalidade são prefixos.

10 Não vamos nos comprometer com o rótulo da posição na qual -wak ocorre. 
A proposta em (17) não derivaria as condições de verdade da sentença, uma vez que, como Maria estaria dentro da proposição 'Maria cozinhar peixe', - wak não conseguiria recuperar o indivíduo (i.e. a própria Maria) cujos desejos são compatíveis com esses mundos possíveis. A proposta em (18) também não derivaria as condições de verdade porque o vestígio ti seria interpretado como uma variável. Em outras palavras, se (18) estivesse correta, a sentença significaria algo como 'Maria quer que x cozinhe peixe' - e não é isso que ela significa. Propomos uma estrutura na qual - wak não toma uma proposição como argumento, mas sim uma propriedade. Ou seja, ela não estaria acima do vP, mas acima do VP, como em (19):

\section{(19) [ Maria[wak [vpbyhipi'ip ] ] ]}

Semanticamente, - wak toma uma propriedade $\mathrm{P}$ e um indivíduo $x$ como argumentos $\mathrm{e}$ afirma que o conjunto $\mathrm{B}(\mathrm{x})$ são os mundos possíveis compatíveis com os desejos de $x$ no mundo atual, ao passo que $w$ são mundos nos quais $x$ tem a propriedade $P$, como em (20):

(20) $\llbracket w a k \rrbracket^{w}=\lambda \mathrm{P} . \lambda \mathrm{x} . \mathrm{B}(\mathrm{x})(\mathrm{w}) \subseteq \mathrm{P}(\mathrm{x})$

Por exemplo, em (15), wak- toma a propriedade de cozinhar peixe como argumento e o indivíduo Maria e afirma que os mundos possíveis compatíveis com os desejos da Maria em $w$ são mundos possíveis nos quais ela possui a propriedade de cozinhar peixe como ilustrado em (21) abaixo.

(21) $\llbracket$ Maria nabyhipiwak 'ip $\rrbracket^{w, g}=1$ sse $B($ Maria $)(w) \subseteq\left\{w^{\prime}\right.$ : Maria cozinha peixe em w' $\}$

Lê-se: A sentença 'Maria nabyhipiwak -'ip' é verdadeira se e somente se o conjunto de mundos possíveis $\mathrm{B}$ compatíveis com os desejos de Maria estiver contido no conjunto de mundos nos $W$ 'nos quais Maria cozinha peixe.

O efeito que isso tem é que - wak só pode ser empregado quando o indivíduo possui um desejo em relação a uma propriedade que se aplica a si mesmo. Por exemplo, o - wak pode ser usado em (16), pois nos mundos dos desejos da Maria, a Maria tem a propriedade de cozinhar peixe. O sufixo - wak não poderia ser empregado, digamos, para expressar algo como 'Maria quer que Joana cozinhe' porque, nesse caso, a Maria estaria atribuindo a propriedade a outro indivíduo.

Apresentamos nessa subseção nossa análise para o sufixo - wak empregando a proposta tradicional para modalidade bulética com algumas poucas modificações para que wak tome uma propriedade - e não uma proposição - como argumento. Não seria possível aplicar a semântica proposta por Kratzer $(2006$; 2016) a -wak, uma vez que a operação Restrict que a autora assume não conseguiria compor - wak com byhip 'ip ('cozinhar peixe'), 
porque Restrict compõe dois predicados e byhip 'ip não seria um predicado." A próxima subseção apresentará a análise para o verbo pyting.

\subsection{O VERBO PYTING}

O verbo pyting pode tomar um NP como argumento, como ilustrado em (22a), ou uma sentença, como em (22b):

$\begin{array}{clc}\text { (22) a. 'Ip-i-ty } & \varnothing \text {-na-pyting- } \varnothing & \text { Maria } \\ \text { peixe-V.E.-OBL } & \text { 3-DECL-querer-NFUT } & \text { Maria }\end{array}$

'Maria quer peixe'

b. [lp-i-ty Maria ti'y-ka ]-ty ø-na-pyting- $\varnothing \quad$ José

[peixe-V.E.-OBL Maria comida-fazer]-OBL 3-DECL-querer-NFUT José

'José quer o cozimento do peixe pela Maria.'

Poderíamos assumir uma análise no qual pyting toma uma proposição e um indivíduo e afirma que essa proposição é verdadeira nos mundos dos desejos do indivíduo como na proposta ilustrada em (23a). No entanto, seguimos uma análise na qual as sentenças em Karitiana são nominalizadas (VIVANCO, 2018). Ou seja, na prática, ambos os argumentos do verbo em (22a-b) são NPs. Dessa forma, as características morfossintáticas do Karitiana parecem indicar que pyting não é um verbo de atitude proposicional e corroborar a proposta de Kratzer (2006; 2016) de que o argumento que ele toma é sempre um NP e nunca uma proposição, como na proposta ilustrada em (23b) abaixo.
(23) a. $\llbracket p y \operatorname{ting} \rrbracket^{w}=\lambda p . \lambda x . \operatorname{DES}(x)(w) \subseteq p$
(Proposta 1)
b. $\llbracket p y \operatorname{ting} \rrbracket^{w}=\lambda x \cdot \lambda s \cdot Q U E R E R(x)(s)(w)$
(Proposta 2)

Ao derivar as condições de verdade de pyting usando (23a), teríamos condições de verdade muito semelhantes às de -wak exemplificadas em (21), com a diferença de que pyting permitiria relacionar os mundos possíveis dos desejos ao conjunto de mundos possíveis denotados por qualquer proposição e não só aquelas nos quais o sujeito atribui as propriedades a si mesmo. Ou seja, poderíamos usar wak- em uma sentença como 'Maria quer cozinhar' porque nela a Maria atribui a propriedade de cozinhar a si mesma e é essa a condição

11 Lembre que na proposta da autora o argumento externo é introduzido pelo $v$, então byhip 'ip não teria nenhum argumento $\mathrm{x}$ para ser saturado. 
necessária para o uso de wak-. Em uma sentença como 'Maria quer que João cozinhe', a Maria não atribui uma propriedade a si mesma, mas ao João. Nesses contextos, pyting é usado.

Outra possibilidade é derivar as condições de verdade usando a proposta de Kratzer (2006; 2016), como mostraremos a seguir. Quando pyting se compusesse com um NP simples, como 'ipi ('peixe'), na sentença (23a), essa composição se daria via operação Restrict e o resultado dessa composição é o representado em (24):

(24) 【'ipity napyting $\rrbracket^{w}=\lambda x \cdot \lambda$ s.QUERER $(x)(s)(w) \& P E I X E(x)$

Lê-se: 'ipity napyting' é um predicado que toma $x$ e s e retorna o estado $s$ de querer $x$ em we $x$ é peixe.

Quando pyting se compõe com uma sentença nominalizada como (23b), assumiremos que o papel do nominalizador é o mesmo que o do complementizador. Lembre-se de que na proposta de Kratzer (2006; 2016) apresentada na seção 3, os verbos não podem tomar proposições como argumento e é papel do complementizador transformar a proposição em predicado para que esse predicado se junte com o verbo via Restrict. Assumiremos que a nominalização é outra forma pela qual uma proposição é transformada em predicado para que a operação Restrict possa ocorrer. Assim, o nominalizador $n$ teria a semântica em (9) e a sentença nominalizada seria um predicado como em (10), que se comporia com o verbo via operação Restricte o resultado dessa composição é o representado em (25):

(25) $\llbracket^{\prime}$ ipity Maria ti'ykaty pyting $\rrbracket^{w}=\lambda x . \lambda s$.querer $(x)(s)(w) \& \forall w^{\prime} \quad$ [compatível $(x)\left(w^{\prime}\right) \rightarrow$ Maria cozinha peixe em $w]$

Lê-se: 'ipity Maria ti'ykaty napyting' toma um xe um se afirma que sé o estado de querer $x$ em $w$ e que para todo mundo $w$ ', se $x$ é compatível com w', Maria cozinha peixe em $w$ '.

Outra característica relevante de pyting parece corroborar a proposta de Kratzer (2006; 2016): ele é um verbo intransitivo. Observe que tanto 'ip ('peixe') quanto 'ipity Maria ti'yka (o cozimento do peixe pela Maria) são marcados pelo caso oblíquo indicando que esses não são argumentos do verbo (SILVA, 2011). Ou seja, o fato desses NPs não serem um argumento do verbo pode ser uma evidência de que a composição entre verbo e objeto não satura um argumento - e é isso que a operação Restrict proposta por Kratzer (2006; 2016) faz.

Esta seção apresentou uma análise para a semântica de pyting. É possível derivar as condições de verdade da sentença assumindo que esse é um verbo de atitude proposicional ou assumindo a proposta de Kratzer (2006; 2016). No entanto, vimos que as características desse verbo corroboram a segunda, uma vez que os verbos em Karitiana tomam uma oração nominalizada como argumento. A próxima subseção apresentará a análise para o verbo py’eep. 


\subsection{O VERBO PY'EEP}

Argumentamos que há apenas uma análise capaz de explicar a contribuição semântica de py'eep para a sentença: esse é um verbo de atitude proposicional. Py'eep expressa modalidade bulética juntamente com negação, como em (26):
(26) Maria $\emptyset$-na-aka-t i-py'eep- $\varnothing \quad$ Antônio moto-ty José amy-ty'12 Maria 3-DECL-COP-NFUT 3-não.querer-ADV Antônio moto-OBL José comprar-OBL 'Maria não quer que José compre a moto do Antônio.'

O verbo py'eep tem as mesmas propriedades de pyting, ou seja, ele toma uma subordinada nominalizada e esse NP não é um argumento do verbo. No entanto, não é fácil atribuir uma semântica para py'eep da mesma forma como fizemos com pyting, seguindo Kratzer (2006; 2016). Poderíamos indicar que a negação está lexicalmente codificada e o verbo expressa um estado de não querer, como em (27):

(27) $\llbracket p y^{\prime} e e p \rrbracket^{w}=\lambda x \cdot \lambda s . n a ̃ o . q u e r e r(x)(s)(w)$

No entanto, a semântica que atribuímos ao nominalizador ainda exige que $x$ seja compatível com todos os mundos possíveis $w$ '. Ou seja, se a composição semântica do py'eep seguisse os mesmos passos que o do pyting, o significado após a operação Restrict seria o seguinte:

(28) $\llbracket p y^{\prime}$ eep Antôniomototy José amyty $\rrbracket^{w}=\lambda x . \lambda s . N A ̃ O . Q U E R E R(x)(s)(w) \& \forall w^{\prime}$ [compatível $(\mathrm{x})\left(\mathrm{w}^{\prime}\right) \rightarrow$ José compra a moto do Antônio em $w$ ]

Temos aqui um impasse: se w'são os mundos dos desejos da Maria, $x$ não deveria ser compatível com eles, visto que $x$ é algo que o sujeito não quer. Poderíamos argumentar que, uma vez que o verbo significa 'não querer', w' são os mundos fora dos desejos da Maria, ou seja, todos os mundos que não estão em $D(x)(w)$. Entretanto, se isso fosse verdade, a sentença afirmaria que todos os mundos fora do conjunto $D(x)(w)$ são compatíveis $\operatorname{com} x$, mas não diria nada sobre o conjunto $\mathrm{D}(\mathrm{x})(\mathrm{w})$ per se, ou seja, não diria nada sobre os mundos dos desejos da Maria. Se isso fosse verdade, uma sentença como (26) deveria expressar indiferença da Maria em relação à compra da moto. No entanto, a terceira fase da nossa 
elicitação ilustrada no exemplo (15) da seção 3 mostrou que Maria não é indiferente à compra da moto quando py’eepé empregado.

No entanto, a semântica de py'eep pode ser dada facilmente quando o analisamos como um verbo de atitude proposicional. Como ilustrado em (29) abaixo, poderíamos assumir que esse verbo denota a intersecção do conjunto dos mundos possíveis compatíveis com os desejos com o conjunto de mundos possíveis da proposição é vazia. Em outras palavras, $p$ não é verdadeira em nenhum dos mundos possíveis compatíveis com os desejos de $x$.

(29) $\llbracket p y^{\prime} e e p \rrbracket^{w}=\lambda p . \lambda x . D(x)(w) \cap p=Q$

Lê-se: $p y^{\prime}$ eep toma uma proposição $p$ e um indivíduo $x$ e expressa que a interseção dos mundos possíveis compatíveis com os desejos de $x$ em $w$ com os mundos denotados pela proposição é vazia.

Esta seção analisou três itens que são responsáveis por expressar modalidade bulética em Karitiana. A próxima seção traz as conclusões deste artigo.

\section{CONCLUSÕES}

Vimos que as características morfossintáticas dos verbos pyting e py’eep do Karitiana parecem corroborar a proposta de Kratzer $(2006$; 2016) de que verbos que parecem tomar uma proposição não são verbos de atitude proposicional. No entanto, capturar a semântica de py'eepse mostrou desafiador dentro dessa proposta. A única maneira de descrever adequadamente a contribuição semântica de - wak, pyting e py'eep é adaptando a teoria padrão assumindo que eles operam relacionando indivíduos e proposições. Assim, admitimos que a nominalização no Karitiana é semanticamente vácua e que uma oração nominalizada ainda remete a uma proposição.

\section{AGRADECIMENTOS}

Agradeço ao CNPq e à CAPES pelas bolsas recebidas durante o doutorado no Brasil e o sanduíche nos Estados Unidos, respectivamente. Também agradeço aos consultores Karitiana que participaram da elicitação que resultou nesta pesquisa. Este artigo se beneficiou de discussões com Marcelo Ferreira, Kai von Fintel, Sabine latridou e Patrick Elliott. Claro que eventuais erros são de responsabilidade do autor. 


\section{REFERÊNCIAS}

FERREIRA, L. F. Modo em Karitiana. São Paulo: Dissertação (mestrado) - Faculdade de Filosofia, Letras e Ciências Humanas, Universidade de São Paulo, 2017a.

FERREIRA, L. F. Karitiana: Uma língua com dupla marcação de modo. Anais do X Congresso Internacional da ABRALIN, Niterói, 2017b. 272-282.

HACQUARD, V. Modality. In: MAIENBORN, C.; VON HEUSINGER, K.; PORTNER, P. Semantics: An international Handbook of Natural Language Meaning. HSK 33.2. Berlin: Mouton de Gruyter, 2011. p. 1484-1515.

KRATZER, A. Modality. In: VON STECHOW, A.; WUNDERLICH, D. Semantik/Semantics. An international Handbook of Contemporary Research. Berlin: de Gruyter, 1991. Cap. 29, p. 639-650.

KRATZER, A. Decomposing attitude verbs. Handout from a talk honoring Anitta Mittwoch on her 80th birthday at the Hebrew University of Jerusalem. [S.I.]: [s.n.]. 2006.

KRATZER, A. Modals and Conditionals. New York: Oxford University Press, 2012.

KRATZER, A. Evidential moods in attitude and speech reports. Slides from a colloquium at UConn. [S.I.]: [s.n.]. 2016.

KRATZER, A.; HEIM, I. Semantics in generative grammar. Oxford: Blackwell, 1998.

LOUIE, M. The problem with NoNonsense Elicitation Plans for Semantic Fieldwork. In: BOCHNAK, M. R.; MATTHEWSON, L. Methodologies in Semantic Fieldwork. [S.I.]: Oxford University Press, 2015. Cap. 2, p. 47-71.

MATTHEWSON, L. On the methodology os semantic fieldwork. International Journal of American linguistics, 70, 2004. 369-415.

SANCHEZ-MENDES, L. Trabalho de campo para análise linguística em semântica formal. Revista Letras, Curitiba, p. 277-293, 2014.

SILVA, Ivan Rocha da. A estrutura argumental da língua karitiana: desafios descritivos e teóricos. 2011 Dissertação (Mestrado em Semiótica e Lingüística Geral) - Faculdade de Filosofia, Letras e Ciências Humanas, Universidade de São Paulo, São Paulo, 2011. doi:10.11606/D.8.2011.tde-12092012-120027

STORTO, L. R. Algumas categorias funcionais em Karitiana. Encontro internacional de grupos de trabalho sobre línguas indígenas. Línguas Indígenas Brasileiras: Fonologia, gramática e história, 2002. 151-164.

STORTO, L. R. Subordination in Karitiana. Ameríndia: Revue d'Ethnolinguistique Amérindienne, Paris, p. 183203, 2012.

STORTO, L. R. Negation in Karitiana. Wa7 xweysás i nqwal'utteniha i ucwalmícwa: He loves the people's language: Essays in honour of Henry Davis, 2018. 227-238.

VIVANCO, K. Orações relativas em karitiana: um estudo experimental. São Paulo: Dissertação (Mestrado) Universidade de São Paulo, 2014.

VIVANCO, K. Perguntas Qu-, orações subordinadas e ordem de palavras em Karitiana. São Paulo: Tese (Doutorado) - Universidade de São Paulo, 2018.

VON FINTEL, K. Modality and language. In: BORCHERT, D. M. Encyclopedia of Philosophy. 2a . ed. Detroit: MacMillan Reference USA, 2006. p. 1-16.

VON FINTEL, K.; HEIM, I. Intensiona/ Semantics. Cambridge: [s.n.], 2011.

VON FINTEL, K.; IATRIDOU, S. the Linguistics of Desire. First Handout for the Seminar 'The Linguistics of Desire'. [S.I.]: [s.n.]. 2017. 